\title{
Sorption behavior of dodecylbenzene sulfonic acid on humic acids from Mollisol and Alluvial soils
}

\author{
Nan Zhao ${ }^{1,2} \cdot$ Yizhong $\mathrm{Lv}^{1} \cdot$ Guixue Song $^{3} \cdot$ Jing Zhang ${ }^{2}$
}

Received: 1 March 2015/ Accepted: 4 November 2015/Published online: 19 February 2016

(C) Springer-Verlag Berlin Heidelberg 2016

\begin{abstract}
Dodecylbenzene sulfonic acid (DBSA), the acid form of sodium dodecylbenzenesulfonate (SDBS), is often identified and detected in soils. However, it still has less awareness of the sorption behavior of DBSA with soil organic matter. In this paper, the sorption behaviors of DBSA on two different types of soils (Mollisol and Alluvial soils) and soil humic acids (HAs) were studied and compared, and the mechanisms of HAs and DBSA interactions were discussed. Sorption dynamics and isotherms were studied using the batch equilibrium method. The sorption kinetics was relatively slow, and the sorption equilibrium can be reached within $10 \mathrm{~h}$. In the designed concentration range of DBSA in this work, the maximum DBSA sorption capacities on the Alluvial soil HA (AHA) and the Mollisol soil HA (MHA) were 115.0 and $112.2 \mathrm{mg} /$ $\mathrm{g}$, respectively, which were higher than those of the Alluvial soil (AS) and Mollisol soil (MS). The sorption isotherms were well fitted by the Freundlich equation. The sorption capacity of the AHA was greater than that of the MHA, AS and MS. Furthermore, the sorption complexes of HAs and DBSA were characterized using elemental analysis, micro-Fourier transform infrared spectroscopy (FTIR), solid-state ${ }^{13} \mathrm{C}$ nuclear magnetic resonance (NMR)
\end{abstract}

Yizhong Lv

lyz@cau.edu.cn

1 College of Resources and Environmental Sciences, China Agricultural University, Beijing 100193, People's Republic of China

2 Department of Environmental Nano-materials, Research Center for Eco-Environmental Sciences, Chinese Academy of Sciences, Beijing 100085, People's Republic of China

3 Pony Testing Co. Ltd, Beijing 100083, People's Republic of China spectroscopy and electron spin resonance spectroscopy (ESR), it reveals that the sorption of DBSA on HAs mainly occurred on the $\mathrm{C}=\mathrm{O}, \mathrm{C}-\mathrm{O}$ and aromatic functional groups. Moreover, the sorption data indicated that the sorption behavior was complicated, probably due to the formation of $\mathrm{H}$ bonds, hydrophobic interactions and electron donoracceptor mechanisms.

Keywords Dodecylbenzene sulfonic acid · Humic acids . Sorption behavior · Mollisol soil · Alluvial soil

\section{Introduction}

Sodium dodecylbenzenesulfonate (SDBS), the most widely used surfactant, is regarded as an important soil contaminant and is often present in sewage sludge, solid waste, industrial waste and waste water (Sablayrolles et al. 2009). As one of the anionic surfactants that is used extensively worldwide, dodecylbenzene sulfonic acid (DBSA) is the acid form of SDBS. Short-term exposure of humans to DBSA results in eye, skin and respiratory tract irritation (US Coast Guard 1984). DBSA is harmful to aquatic organisms, animals, soils and plants. To reduce surfactant contamination, it is important to study the sorption process of the acid form of SDBS and to better understand the interactions of surfactants with soil organic matter (SOM). To the best of our knowledge, the sorption behaviors of DBSA with SOM remain unclear. In this work, we focused on the sorption behavior of DBSA with one of its main fractions, humic acids (HAs) (Senesi 1992).

The sorption behaviors of surfactants with HAs can simulate the occurrence and transportation of surfactants sorbed onto SOM. Although the sorption behaviors of SDBS have been reported, the sorption behaviors of DBSA 
on soils and HAs remain unknown. Fernández-Ramos et al. (2014) studied the sorption characteristics of alcohol sulfate in soils, the sorption equilibrium was reached in $1 \mathrm{~h}$, the sorption isotherms were fitted by linear and Freundlich models well. Rodríguez and Pinzón-Bello (2001) investigated the surfactant sorption of SDBS on organophilic bentonite. In this case, sorption was relatively quick which was better described by the Langmuir isotherm model. For the sorption of aldicarb and SDBS on dried soil, a linear sorption isotherm fit the data well (Dai et al. 2001).

Rodríguez-Cruz et al. (2005) studied adsorption of sodium dodecyl sulphate on eighteen soils, indicating that SOM can greatly affect the adsorption capacity. Up to now, the sorption behavior of DBSA on SOM is still not well understood. Because HA is normally the main fraction of SOM, therefore, HAs' interactions with DBSA should be studied first in order to determine the sorption behavior of SOM with DBSA. DBSA contains hydrophobic and hydrophilic heads in the structure, and HAs was reported to have many hydrophobic and hydrophilic functional groups (Hsieh et al. 2012). Thus, the hydrophobic interactions among these groups play an important role for the sorption mechanisms of DBSA to HA. In the paper, we selected two HAs samples extracted from Mollisol and Alluvial soils to study sorption behaviors, mechanisms and their differences of DBSA onto HAs. The soils were chosen because they are two representative soil types, and their significant differences of chemical and physical properties, meanwhile, SOM contains greater amount of HAs, and HAs in the two soils are relatively easy to extract and obtained. Untreated HAs and HAs-DBSA complexes were comprehensively characterized using elemental analysis, micro-Fourier transform infrared (FTIR) spectroscopy, solid-state ${ }^{13} \mathrm{C}$ nuclear magnetic resonance (NMR) spectroscopy and electron spin resonance spectroscopy (ESR) to study the sorption mechanisms and predict the fate of DBSA in the environment.

\section{Materials and methods}

\section{Materials}

The DBSA was purchased from TCI (TCI Shanghai, China) with a purity of $>90 \%$. The critical micelle concentration (CMC) is reported as $0.4134 \mathrm{~g} \mathrm{~L}^{-1}$ (Ando et al. 2012). It is soluble in water.
The Mollisol soil (clay loam) was kindly provided from the Long-term Experiment Station, Jilin Academy of Agricultural Sciences $\left(43^{\circ} 31^{\prime} \mathrm{N}, 124^{\circ} 48^{\prime} \mathrm{E}\right)$, where the annual average temperature was $5.6^{\circ} \mathrm{C}$ and the mean annual rainfall was $562 \mathrm{~mm}$. The parent material was quaternary loess sediment. The Alluvial soil (clay loam) was obtained from the Dry-Land Farming Institute, Hebei Academy of Agricultural and Forestry Sciences $\left(37^{\circ} 44^{\prime} \mathrm{N}\right.$, $\left.115^{\circ} 42^{\prime} \mathrm{E}\right)$. The station altitude is about $50.1 \mathrm{~m}$, located in the monsoon region of east China, where the annual average temperature was $12.2^{\circ} \mathrm{C}$, the mean annual rainfall was $522.5 \mathrm{~mm}$, and the frost-free period is about $200 \mathrm{~d}$ each year (Zhao et al. 2013). Soil samples were collected from the top layer $(0-20 \mathrm{~cm})$, air-dried and passed through a 2-mm sieve. The soil properties are shown in Table 1.

The HAs were extracted following the standard IHSS method (Swift 1996). Briefly, the samples were pretreated with $1 \mathrm{~mol} / \mathrm{L} \mathrm{HCl}$ to remove $\mathrm{CaCO}_{3}$ before extracting with $1 \mathrm{~mol} / \mathrm{L} \mathrm{NaOH}$. The experiment was conducted under $\mathrm{N}_{2}$ gas to prevent oxidation. The alkaline supernatant solution was separated by centrifugation at $5000 \mathrm{rpm}$ and acidified with $6 \mathrm{~mol} / \mathrm{L} \mathrm{HCl}$ to $\mathrm{pH} \mathrm{1.} \mathrm{The} \mathrm{dialysis} \mathrm{was} \mathrm{repeated}$ against water to purify the HAs. Finally, each sample was freeze-dried and ground to pass through a $0.25-\mathrm{mm}$ sieve before being stored in a desiccator.

\section{Procedures}

An aliquot of DBSA solution (20 ml, $120 \mathrm{mg} / \mathrm{L})$ was added to the solid HAs $(0.06 \mathrm{~g})$ in a $50 \mathrm{ml}$ stoppered reaction vessel, and the solution was shaken and dispersed. Microbial growth was prevented by a few sodium azide. Sorption was allowed to proceed on a shaker with an amplitude of $13 \mathrm{~mm}$ at $130 \mathrm{rpm}$ and at $25 \pm 1{ }^{\circ} \mathrm{C}$. The shaking intervals were $0,2,5,10,16,24,36,48,60$, and $72 \mathrm{~h}$, respectively. After shaking, the supernatant solutions were collected by centrifugation (5000 rpm, $12 \mathrm{~min}$ ) and filtered through a $0.22-\mu \mathrm{m}$ membrane (Millex-HV). The DBSA concentration was determined colorimetrically using UV-vis spectroscopy. Briefly, the absorbance was recorded at $223 \mathrm{~nm}$ using purified water as a blank and a control without DBSA after stirring for the same time intervals mentioned above. All experiments were carried out in triplicate to determine the rate of sorption.

Aliquots of DBSA $(20 \mathrm{ml})$ were spiked with $0.06 \mathrm{~g} \mathrm{HAs}$ in $50 \mathrm{ml}$ stoppered reaction vessels. The initial

Table 1 Soil properties

\begin{tabular}{llllllll}
\hline Sample & $\mathrm{pH}$ & OM content $(\%)$ & Moisture content $(\%)$ & Bulk density $\left(\mathrm{g} \mathrm{cm}^{-3}\right)$ & Clay $(\%)$ & Sand $(\%)$ & Silt $(\%)$ \\
\hline Mollisol soil & 5.44 & 2.71 & 3.93 & 1.20 & 31.98 & 17.24 & 50.78 \\
Alluvial soil & 7.65 & 1.59 & 2.00 & 1.14 & 19.00 & 16.81 & 64.19 \\
\hline
\end{tabular}


concentration of DBSA ranged from 15 to $360 \mathrm{mg} / \mathrm{L}$. The maximum concentration used was lower than critical micelle concentration. Equilibration was achieved by shaking for $48 \mathrm{~h}$ at $130 \mathrm{rpm}$ and $25 \pm 1{ }^{\circ} \mathrm{C}$. Preliminary studies indicated that equilibration could be completely stable within $48 \mathrm{~h}$. The DBSA was measured at $223 \mathrm{~nm}$ by using purified water as a blank. In addition, no DBSA was added to the control samples. All experiments were carried out in triplicate to determine the sorption isotherms.

The amount of sorbed DBSA on soils and HAs was calculated from the mass balance equation $q_{e}=$ $V\left(C-C_{e}\right) / m$, and the sorption isotherms were constructed using the sorption data and were fitted using the following three equations:

(a) the linear equation

$q_{e}=K_{P} C_{e}$,

(b) the nonlinear Langmuir equation

$q_{e}=K a C_{e} /\left(1+K C_{e}\right)$ and

(c) the Freundlich equation $q_{e}=K_{F} C_{e}^{n}$, where

$q_{e}$ is the amount of DBSA (mg) sorbed per unit weight (g) of HA, $V$ is the volume of DBSA solution $(20 \mathrm{ml}), C$ is the initial concentration of DBSA $(\mathrm{mg} / \mathrm{L}), C_{e}$ is the equilibrium concentration of the DBSA solution $(\mathrm{mg} / \mathrm{L}), K_{P}$ is the partition coefficient, $K$ is the sorption coefficient, $K_{F}$ is the characteristic constants, $n$ is the sorption intensity, and $a$ is the Langmuir sorption maximum (Kasozi et al. 2010; Benoit et al. 1998; Chen et al. 2011).

\section{Preparation of HAs-DBSA complexes}

The preparation of HAs-DBSA complexes was conducted according to Senesi et al. (1994). HAs (0.06 g) were added to a $50 \mathrm{ml}$ stoppered reaction vessels with $20 \mathrm{ml} 360 \mathrm{mg} / \mathrm{L}$ DBSA solution and were shaken for $48 \mathrm{~h}$. Then the mixtures were centrifuged at $5000 \mathrm{rpm}$ for $12 \mathrm{~min}$. The treatment was repeated twice. Finally, the HAs-DBSA complexes were washed twice with purified water and freeze-dried for further analysis.

\section{Sorption mechanism}

The untreated HAs and their interaction products were characterized using elemental analysis, micro FT-IR, solidstate ${ }^{13} \mathrm{C}$-NMR and ESR. The $\mathrm{C}, \mathrm{H}$, and $\mathrm{N}$ concentrations were measured using a Vario EL III elemental analyzer (Elementar, Germany). The $\mathrm{O}$ content was obtained by subtraction $(\mathrm{O} \%=100-\mathrm{C} \%-\mathrm{H} \%-\mathrm{N} \%)$. The FTIR spectra were obtained using a Nicolet Magna-IR ${ }^{\mathrm{TM}} 750$ microinfrared spectrometer with a KBr-beam splitter. Next, 128 scans were collected at a resolution of $3 \mathrm{~cm}^{-1}$. The scan range was $600-4000 \mathrm{~cm}^{-1}$, and a MCT-A detector (Thermo Scientific, Madison, WI) was used. For each measurement, about $0.1 \mathrm{mg}$ of sample was used. The FTIR spectra were recorded in triplicate and averaged for each sample. The solid-state ${ }^{13} \mathrm{C}-\mathrm{NMR}$ spectra were obtained using a Bruker Avance III 400 instrument (Bruker, Switzerland) with a $4-\mathrm{mm}$ probe at a spinning speed of $5 \mathrm{kHz}$ and a spectrometer frequency of $100.38 \mathrm{MHz}$. The acquisition conditions included a contact time of $3000 \mu \mathrm{s}$, a recycling time of $2 \mathrm{~s}$ and a scan number of more than 10,000. The spectra were acquired using cross-polarization magic-angle-spinning and total sideband suppression ( $\mathrm{CP}$ TOSS) (Mao et al. 2012). The sample amount (air-dried) was approximately $0.20 \mathrm{~g}$, and a line broadening of $100.00 \mathrm{~Hz}$ was used for processing the spectra. The ESR spectra of the organic free radicals in the HA samples were obtained using a Bruker ESP300 spectrometer (Bruker Bio Spin, Billerica, MA, USA) operating at frequency with a magnetic field modulation $100 \mathrm{kHz}$ at room temperature for solid samples that were packed in quartz ESR tubes. The ESR spectra were measured at a microwave frequency of $9.75 \mathrm{GHz}$ and at a microwave power of $10 \mathrm{~mW}$.

\section{Results and discussion}

\section{Sorption kinetics}

Figure 1 shows the sorption kinetics of the DBSA on the soils and HAs. The sorption rate of DBSA on soils and HAs was relatively slow, and the equilibrium was approached within $10 \mathrm{~h}$, which indicated that the association of DBSA molecules with the soils and HAs occurred relatively slowly. The sorption rate of DBSA on Alluvial soil HA (AHA) was faster than that of Mollisol soil HA (MHA) and soils. The amount of DBSA per unit mass of AHA (including the equilibrium sorption) was greater than that of the MHA (35.73 vs. $29.00 \mathrm{mg} / \mathrm{g}$ ). For the Alluvial soil, this figure was greater than that of Mollisol soil. This indicated that there was no relationship between the sorption amount and the SOM due to a relatively lower SOM content for Alluvial soil. The maximum removal of DBSA on MHA was exhibited within $10 \mathrm{~h}$. Then, the sorption amount decreased until $16 \mathrm{~h}$ and then increased. This result indicated that the desorption may occur at the same time as the sorption due to their reversible process for desorption and sorption (Yu et al. 2001). In addition, this phenomenon occurred for the AHA, MS and AS. Furthermore, some HAs may be solubilized due to the solubilizing mechanism of DBSA, which can promote dissolution of humic acids (Crecchio and Stotzky 1998). However, the sorption will equilibrate gradually. The amount of DBSA sorbed onto AHA approached its maximum within $5 \mathrm{~h}$ and then slowly reached the equilibrium. The data suggest that DBSA sorption could be divided into two stages: a quick sorption stage at the beginning, then that is followed by a slow 
Fig. 1 DBSA sorption kinetics on soils and HAs. The standard errors are too low to be visible

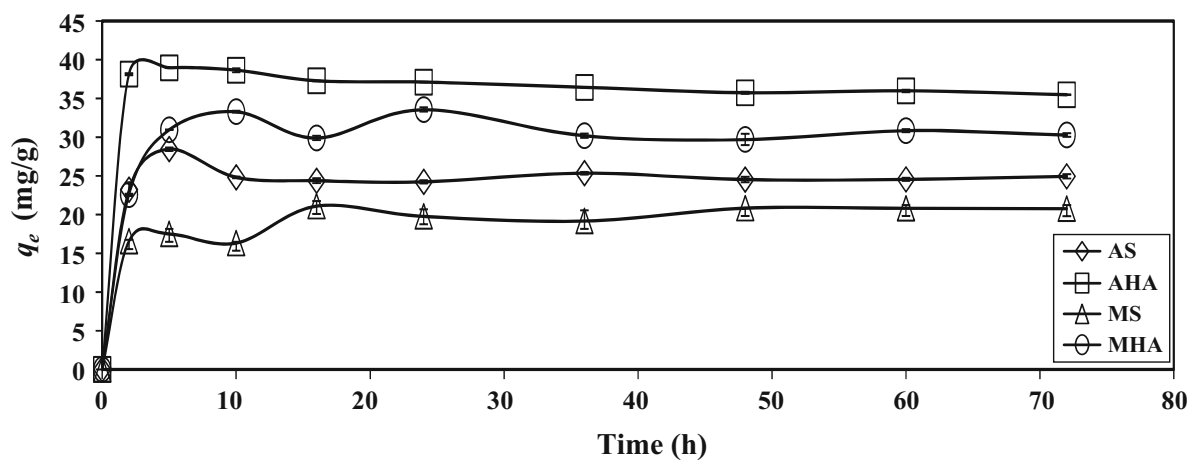

sorption stage. DBSA sorbed by the easily accessed sorption sites and then entered a slow sorption process due to the sorption sites of the HAs that were difficult to access (Li et al. 2002).

\section{Sorption isotherms}

Sorption isotherms were used to determine the sorption capacities of DBSA on the soils and HAs. The DBSA sorption isotherms at different initial DBSA concentrations are shown in Fig. 2. The sorption data were fitted with three isotherm models, i.e., linear, Langmuir and Freundlich isotherms, and the sorption constants and correlation coefficients were calculated from these three isotherms (Table 2). The correlation coefficients $\left(R^{2}=0.935-0.991\right)$ suggested that the Freundlich model fit the data better than the linear (constant partition-type isotherm) and Langmuir models. Overall, the Langmuir model made the fit the poorest. Because $n>1$ shows favorable sorption, the DBSA was easily sorbed onto the HAs and soils. Furthermore, the $K$ value of the AHA for DBSA was larger than the corresponding value for MHA. This result indicated a greater sorbed amount of AHA, potentially due to its higher hydrophobicity (Carmo et al. 2000). For soils, the sorbed amount was greater for the Alluvial soil than the Mollisol soil. In summary, DBSA can be intimately sorbed by the heterogeneous surface of HAs (Yao et al. 2013).

\section{Sorption mechanism of the DBSA on HAs}

The elemental composition and atomic ratios for the HAs and their interaction complexes are listed in Table 3.

Fig. 2 Sorption isotherms for DBSA on two different soils and soil HAs (lines represent Freundlich sorption isotherms). The standard errors are too low to be visible

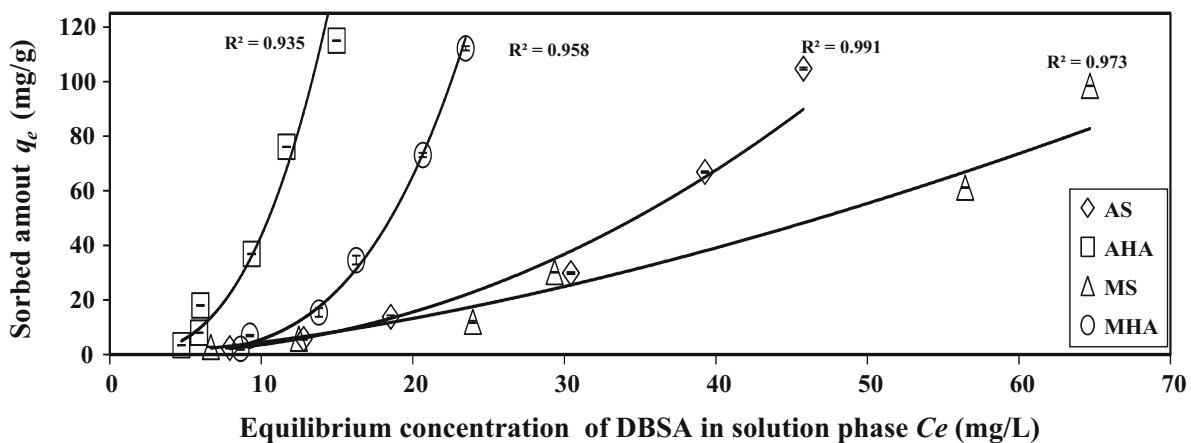

Table 2 Parameters for DBSA different sorption isotherm equations

\begin{tabular}{|c|c|c|c|c|c|c|c|c|}
\hline \multirow[t]{2}{*}{ Sample } & \multicolumn{2}{|l|}{$\begin{array}{l}\text { Linear } \\
q_{e}=K_{P} C_{e}\end{array}$} & \multicolumn{3}{|c|}{$\begin{array}{l}\text { Langmuir } \\
q_{e}=K a C_{e} /\left(1+K \mathrm{C}_{\mathrm{e}}\right)\end{array}$} & \multicolumn{3}{|l|}{$\begin{array}{l}\text { Freundlich } \\
q_{e}=K_{F} C_{e}^{\mathrm{n}}\end{array}$} \\
\hline & $K_{P}$ & $R^{2}$ & $K$ & $a$ & $R^{2}$ & $K_{F}$ & $n$ & $R^{2}$ \\
\hline MHA & $3.139 \pm 0.684$ & 0.608 & $-46.18 \pm 5.675$ & $-5.414 \pm 1.535$ & 0.573 & $0.002 \pm 0.008$ & $3.563 \pm 0.114$ & 0.958 \\
\hline AHA & $5.782 \pm 0.055$ & 0.722 & $-69.54 \pm 0.555$ & $-11.49 \pm 0.275$ & 0.555 & $0.057 \pm 0.006$ & $2.885 \pm 0.052$ & 0.935 \\
\hline MS & $1.231 \pm 0.008$ & 0.876 & $-12.00 \pm 0.544$ & $-34.72 \pm 4.751$ & 0.823 & $0.060 \pm 0.009$ & $1.562 \pm 0.056$ & 0.973 \\
\hline AS & $1.686 \pm 0.016$ & 0.770 & $-20.18 \pm 1.077$ & $-15.02 \pm 2.968$ & 0.845 & $0.067 \pm 0.021$ & $2.104 \pm 0.121$ & 0.991 \\
\hline
\end{tabular}

Values are mean \pm standard errors 
Table 3 Elemental composition, atomic ratios of HAs and their interaction complexes

\begin{tabular}{|c|c|c|c|c|c|c|c|c|}
\hline \multirow[t]{2}{*}{ Sample } & \multicolumn{4}{|c|}{ Composition (\%) } & \multicolumn{4}{|c|}{ Atomic ratio } \\
\hline & $\mathrm{C}$ & $\mathrm{H}$ & $\mathrm{N}$ & $\mathrm{O}$ & $\mathrm{H} / \mathrm{C}$ & $\mathrm{O} / \mathrm{C}$ & $\mathrm{C} / \mathrm{N}$ & $(\mathrm{N}+\mathrm{O}) / \mathrm{C}$ \\
\hline MHA & $52.93 \pm 0.071$ & $4.23 \pm 0.078$ & $4.07 \pm 0.004$ & $38.77 \pm 0.050$ & 0.98 & 0.54 & 13.04 & 0.62 \\
\hline MHA-D & $53.33 \pm 0.040$ & $4.70 \pm 0.033$ & $4.29 \pm 0.027$ & $37.63 \pm 0.100$ & 1.06 & 0.53 & 14.50 & 0.60 \\
\hline AHA & $51.17 \pm 0.035$ & $6.07 \pm 0.054$ & $6.73 \pm 0.005$ & $36.03 \pm 0.062$ & 1.42 & 0.53 & 8.87 & 0.63 \\
\hline AHA-D & $54.97 \pm 0.023$ & $5.83 \pm 0.009$ & $5.79 \pm 0.006$ & $33.43 \pm 0.026$ & 1.27 & 0.46 & 11.09 & 0.55 \\
\hline
\end{tabular}

MHA and AHA represent the HAs from the Mollisol soil and the Alluvial soil, and MHA-D and AHA-D represent the corresponding interaction complexes. Values are mean \pm standard errors

Compared to the AHA, the $\mathrm{H}$ and $\mathrm{N}$ contents and $\mathrm{H} / \mathrm{C}$ ratio of the MHA were lower, and the $\mathrm{C}$ and $\mathrm{O}$ contents and $\mathrm{C} / \mathrm{N}$ ratio were greater. This finding indicated that the MHA molecules contained fewer $\mathrm{N}$ containing compounds and more compounds with aliphaticity (Stevenson 1994; $\mathrm{Lu}$ et al. 2000) and O relative to the AHA (Rosell et al. 1978). When comparing these two HAs and their corresponding interaction complexes, the $\mathrm{C}$ content increased and the $\mathrm{O}$ content decreased, which suggested that sorption occurred between the HAs and DBSA (Chao et al. 2013).

The FTIR spectra of MHA, AHA, the interaction complexes (MHA-D, AHA-D) and DBSA are shown in Fig. 3. Several of the absorption peaks in the spectra were significantly different. When comparing the spectrum of the MHA-D with those of the MHA, several major absorption peaks were shifted to lower wavenumbers. For example, a broad band of $3369 \mathrm{~cm}^{-1}$ of MHA was attributed to $-\mathrm{OH}$ and $-\mathrm{NH}_{2}$ stretching vibrations (Deng and Bai 2004) was shifted to $3362 \mathrm{~cm}^{-1}$ in MHA-D, indicating the formation of $\mathrm{H}$ bonds (Baes and Bloom 1989; Wang et al. 1999). The peak at $2930 \mathrm{~cm}^{-1}$ was due to aliphatic $\mathrm{C}-\mathrm{H}$ stretching vibration (Kapoor and Viraraghavan 1997), while the shoulders presented at 1659 and $1628 \mathrm{~cm}^{-1}$, were corresponded to the $\mathrm{C}=\mathrm{O}$ stretching vibrations of quinone and H-bonded conjugated ketones (D'Orazio et al. 1999). After interaction with DBSA, the $\mathrm{C}-\mathrm{O}$ stretching of the polysaccharides or polysaccharide-like substances at $1045 \mathrm{~cm}^{-1}$ was shifted towards a lower wavenumber $\left(1036 \mathrm{~cm}^{-1}\right)$ (Loffredo et al. 1999), which indicated that $\mathrm{H}$ bonds could be formed during the sorption of DBSA and HAs molecules. Several similar sorption experiments demonstrated the formation of $\mathrm{H}$ bonds during the sorption of some pesticides with humic substances (HS), such as the sorption of butachlor on HAs (Xu et al. 2005) and the sorption of $s$-triazine on HS (Senesi et al. 1987). However, FTIR spectra have rarely been applied to study the sorption of surfactants.

The spectra for AHA were different from those of the MHA, as shown in Fig. 3. In Fig. 3, the small peak at $3084 \mathrm{~cm}^{-1}$ represents the resolved aromatic $\mathrm{C}-\mathrm{H}$ group. Although the intensity of the peak at $1658 \mathrm{~cm}^{-1}$ did not

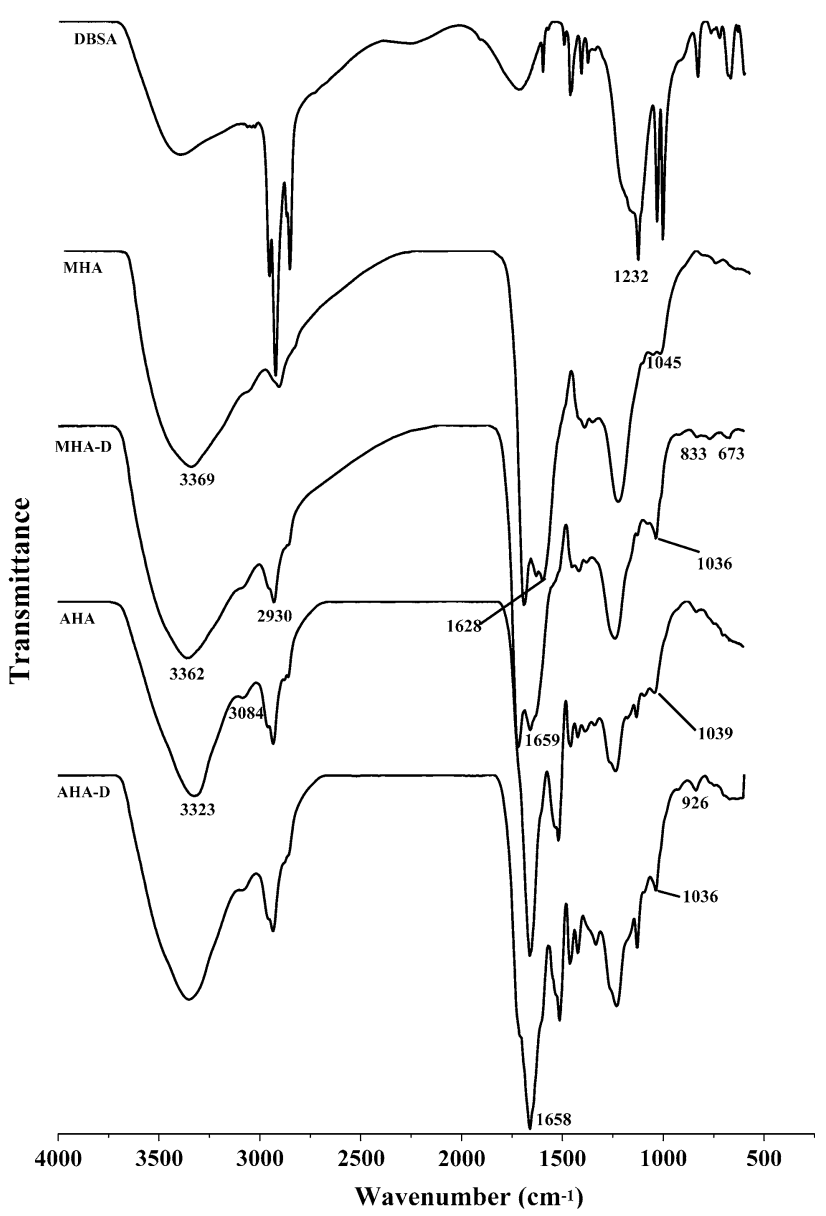

Fig. 3 FTIR spectra of HAs from the Mollisol soil (MHA), Alluvial soil (AHA), their interaction complexes (MHA-D, AHA-D) and DBSA

change, the peak became broader, which could suggest that the sorption occurred on the $\mathrm{C}=\mathrm{O}$ groups. At $1232 \mathrm{~cm}^{-1}$, corresponding to $\mathrm{C}-\mathrm{O}$ stretching vibration in phenols and alcohols (Russell et al. 2006), the increased intensity could indicate the formation of $\mathrm{H}$ bonds (Wang et al. 1999; Baes and Bloom 1989). In addition, electron transfer potentially occurred.

In addition, the fingerprint region $\left(<1000 \mathrm{~cm}^{-1}\right)$ indicated some significant differences. Regarding the MHA-D, 
the peak at $833 \mathrm{~cm}^{-1}$, which represented aryl C-H (Baldock and Skjemstad 2000), and the peak at $673 \mathrm{~cm}^{-1}$ (Yang et al. 2002), which represented substituted benzene rings, were not present in the MHA. For the AHA-D, the peak at $926 \mathrm{~cm}^{-1}$, which represented the aliphatic skeleton (Gu et al. 2000), was not present in the AHA. This data could be ascribed to the shift of some DBSA functional groups, which could be explained by other mechanisms, such as Van der Waals forces (Senesi et al. 1997). The changes between the MHA and MHA-D spectra and the AHA and AHA-D spectra were similar. In summary, the sorption mainly occurred on the $\mathrm{C}=\mathrm{O}$ and $\mathrm{C}-\mathrm{O}$ functional groups of the HAs and the sorption mechanisms were ascribed to form $\mathrm{H}$ bonds among these molecules.

On the other hand, we used ${ }^{13} \mathrm{C}$-NMR to reveal sorption mechanism between DBSA and HAs. Figure 4 showed the solid-state ${ }^{13} \mathrm{C}$-NMR spectra of HAs and their complexes. The intensity distribution of the HAs and the sorption complexes calculated from the solid-state ${ }^{13} \mathrm{C}$-NMR spectra are shown in Table 4. The aliphatic carbon content of the AHA was $46.81 \%$, which was greater than that of MHA. The data indicated that the aliphatic characteristics of AHA are greater than those of MHA. The distribution contents of the carbon functional groups changed after sorption. The carbonyl C content in the MHA was $1.57 \%$, while that in the MHA-D was $7.84 \%$; the aromatic $\mathrm{C}$ in the AHA and AHA-D was 22.10 and $29.05 \%$, respectively. Compared with the other peaks, the changing ratios before and after sorption were the greatest (399.4 and $31.45 \%$ ). The chemical shift of $222 \mathrm{ppm}$ in the MHA-D, attributed to carbonyl carbons (aldehydes, ketones etc.) was absent in MHA. It can be explained that sorption happened on carbonyl carbons. This result was consistent with the IR spectroscopy. A Clear band of aromatic carbons near $152 \mathrm{ppm}$ in AHA-D indicated that sorption also took place in aromatic carbons. DBSA has the hydrophobic end, and the content of the hydrophobic functional group of AHA was greater than that of the MHA. Consequently, the hydrophobic interaction of the AHA was enhanced, and the amount of DBSA sorption on AHA was greater than that on MHA, which was consistent with the results shown in Figs. 1 and 2. The results were also consistent with the findings that the hydrophobic bonding appeared to predominate on low-humified, highly aliphatic sludge HA (Senesi et al. 1994) and that the adsorbents with higher hydrophobic characteristics had greater adsorptive capacities (Leenheer and Ahlrichs 1971). Furthermore, Haigh (1996) claimed that the sorption of anionic surfactants appeared to be affected by a hydrophobic mechanism. The HAs consisted of rich negative charges. However, due to the cleavage of bonds and for other reasons, such as the $-\mathrm{NH}_{3}{ }^{+}$on the HAs, a small amount of positive charge occurred on the surface under acidic conditions in the form
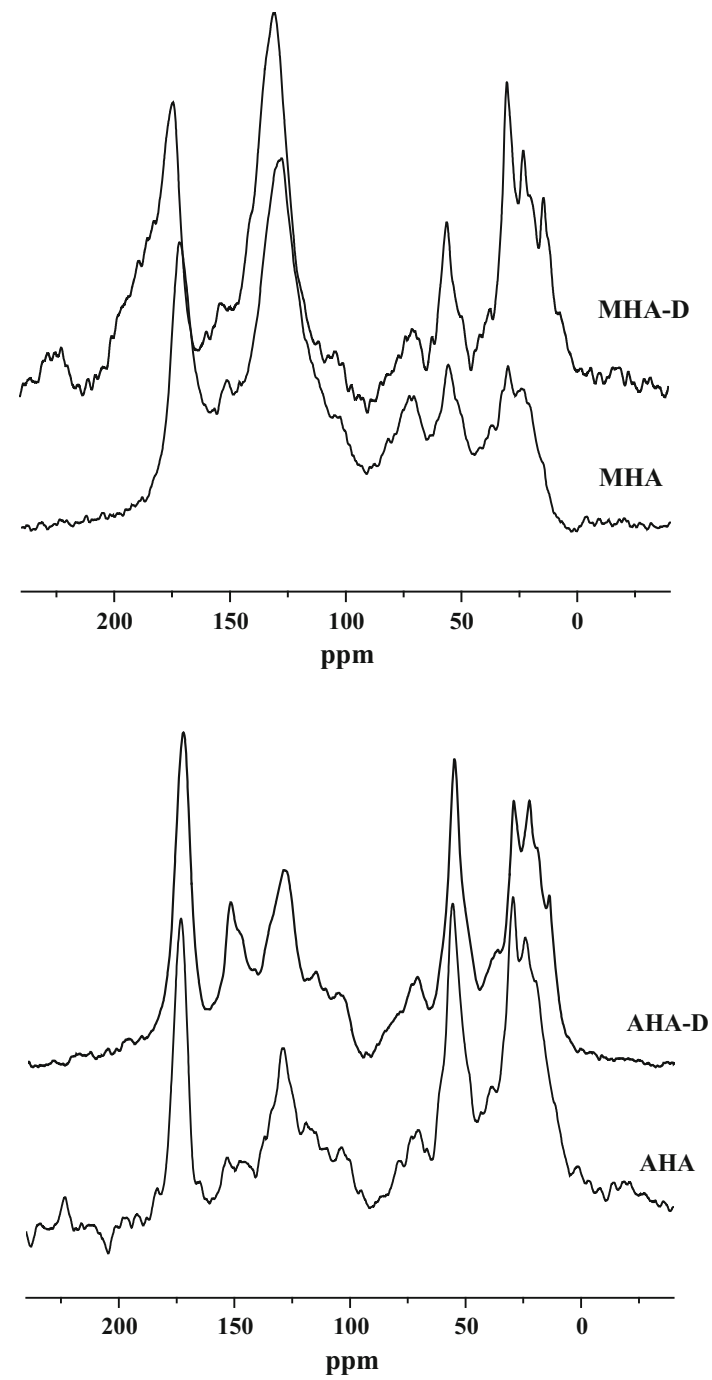

Fig. 4 Solid state ${ }^{13}$ C-NMR spectra of the Mollisol soil HA (MHA), the Mollisol soil HA-DBSA (MHA-D), the Alluvial soil HA (AHA), the Alluvial soil HA-DBSA (AHA-D)

of protonated carboxylic, alcohol and hydroxyl groups (Dong et al. 2011). Because positive and negative charges attract, an electrostatic interaction occurred potentially between the HAs and DBSA.

Moreover, ESR spectroscopy was used to demonstrate changes in the free radicals of HA before and after sorption. In Table 5, the free radical concentrations, line widths and spectroscopic splitting factors ( $\mathrm{g}$ ) of the HAs and HAsDBSA complexes are shown. The g-values for the unsorbed HAs and for the interaction complexes were the same, which indicated that the free radical species did not change. The organic free radical concentrations increased by $734 \%$ and $61.9 \%$ for the MHA-D and AHA-D, respectively, compared to the unsorbed HAs, which contributed to the donor-acceptor interaction between the HA carbonyl group, which acted as electron donors, and the DBSA 
Table 4 Intensity distribution of the ${ }^{13} \mathrm{C}$-NMR spectra of HAs and HAs-DBSA complexes

\begin{tabular}{|c|c|c|c|c|c|c|c|c|c|}
\hline Samples & $\begin{array}{l}\text { Aliphatic } \\
(\%) \\
\delta 0-60\end{array}$ & $\begin{array}{l}\text { Heteroaliphatic } \\
(\%) \\
\delta 60-90\end{array}$ & $\begin{array}{l}\text { Acetal } \\
(\%) \\
\delta 90-110\end{array}$ & $\begin{array}{l}\text { Aromatic } \\
(\%) \\
\delta 110-165\end{array}$ & $\begin{array}{l}\text { Carboxyl } \\
(\%) \\
\delta 165-190\end{array}$ & $\begin{array}{l}\text { Carbonyl } \\
(\%) \\
\delta 190-230\end{array}$ & $\begin{array}{l}\text { Aliphaticity } \\
(\%)\end{array}$ & $\begin{array}{l}\text { Hydrophobic } \\
\text { functional } \\
\text { group }(\%)\end{array}$ & $\begin{array}{l}\text { Hydrophilic } \\
\text { functional } \\
\text { group (\%) }\end{array}$ \\
\hline MHA & 21.56 & 11.63 & 7.27 & 44.50 & 13.47 & 1.57 & 47.62 & 73.33 & 26.67 \\
\hline MHA-D & 32.12 & 4.76 & 2.11 & 34.97 & 18.20 & 7.84 & 52.72 & 69.20 & 30.80 \\
\hline AHA & 46.81 & 10.64 & 5.25 & 22.10 & 12.73 & 2.48 & 73.93 & 74.16 & 25.84 \\
\hline AHA-D & 40.91 & 8.33 & 3.64 & 29.05 & 16.01 & 2.06 & 64.54 & 73.60 & 26.4 \\
\hline
\end{tabular}

Aliphaticity $=C \%(\delta 0-110) / C \%(\delta 0-165)$

Hydrophobic functional group $=$ aromatic + acetal + aliphatic groups

Hydrophilic functional group $=$ heteroaliphatic + carboxyl + carbonyl groups

Table 5 Electron spin resonance (ESR) parameters for HAs and HAs-DBSA complexes

\begin{tabular}{llll}
\hline Sample & $\begin{array}{l}\text { Free radical } \\
\text { concentration } \\
\left(\text { spins } / \mathrm{g} \times 10^{14}\right)\end{array}$ & $\begin{array}{l}\text { Line width } \\
\text { (gauss) }\end{array}$ & $\begin{array}{l}\text { Spectroscopic } \\
\text { splitting }(\mathrm{g})\end{array}$ \\
\hline MHA & 1.102 & 4.0 & 2.004 \\
MHA-D & 9.193 & 3.7 & 2.004 \\
AHA & 0.984 & 4.8 & 2.004 \\
AHA-D & 1.593 & 5.5 & 2.004 \\
\hline
\end{tabular}

aromatic rings, which acted as the electron acceptor (Mattson et al. 1969). The data also indicated that sorption occurred on the carbonyl groups, which was consistent with the analysis results of the FTIR and NMR spectra.

From the above results, we deduced that the fate of DBSA in the environment included three parts: (1) DBSA was mobile and not sorbed by HAs. (2) DBSA was combined with HAs, which changed the structures of HAs. (3) Some proportions of DBSA that may be leached out to the environment as irrigation and rainfall in the natural conditions caused desorption of DBSA with HAs.

\section{Conclusions}

The sorption of surfactants has been shown to play an important role in reducing industrial and agricultural pollution. In this work, the sorption capacities and mechanisms of two different HAs and soils with DBSA were investigated. The sorption rates were relatively small, and the equilibrium can be reached within $10 \mathrm{~h}$. The sorption capacities of the HAs were greater than those of the soils. In addition, HAs are an effective sorbent to reduce the DBSA concentration in the environment. In the concentration range of DBSA set in this experiment, the experimental data for the sorption of DBSA onto two types of HAs and soils were examined and well fitted by the
Freundlich isotherm. It gives the maximum DBSA sorption capacities of $115.0 \mathrm{mg} / \mathrm{g}$ for the Alluvial soil HA and $112.2 \mathrm{mg} / \mathrm{g}$ for the Mollisol soil HA, and SOM did not influence the sorption capacity. The sorption data also demonstrated that the sorption on the Mollisol soil HA and the Alluvial soil HA mainly occurs on $\mathrm{C}=\mathrm{O}, \mathrm{C}-\mathrm{O}$ and aromatic functional groups. In addition, the data suggested that the sorption mechanism mainly consisted of the formation of $\mathrm{H}$ bonds, hydrophobic interactions and electron donor-acceptor mechanisms. Electrostatic interactions could exist during these interactions. The relationships between the sorption properties and the structure characterization of the HAs can give a better understanding on the sorption behavior and the fate of DBSA on HAs.

Acknowledgments This work was supported by the National Natural Science Foundation of China (40771099 and 41271331).

\section{References}

Ando N, Kuwabara Y, Kodama T, Mori YH (2012) Surface tensions of aqueous solutions of lithium dodecyl sulfate, sodium oleate, and dodecylbenzene sulfonic acid in contact with methane under hydrate-forming conditions. Fluid Phase Equilib 314:146-151

Baes AU, Bloom PR (1989) Diffuse reflectance and transmission Fourier transform infrared (DRIFT) spectroscopy of humic and fulvic acids. Soil Sci Soc Am J 53:695-700

Baldock JA, Skjemstad JO (2000) Role of the soil matrix and minerals in protecting natural organic materials against biological attack. Org Geochem 31:697-710

Benoit P, Barriuso E, Calvet R (1998) Biosorption characterization of herbicides, 2.4-D and atrazine, and two chlorophenols on fungal mycelium. Chemosphere 37:1271-1282

Carmo AM, Hundal LS, Thompson ML (2000) Sorption of hydrophobic organic compounds by soil materials: application of unit equivalent Freundlich coefficients. Environ Sci Technol 34:4363-4369

Chao HP, Lee CH, Juang LC, Han YL (2013) Sorption of organic compounds, oxyanions, and heavy metal ions on surfactant modified titanate nanotubes. Ind Eng Chem Res 52:9843-9850

Chen XC, Chen GC, Chen LG, Chen YX, Lehmann J, McBride MB (2011) Adsorption of copper and zinc by biochars produced from 
pyrolysis of hardwood and corn straw in aqueous solution. Bioresour Technol 102:8877-8884

Crecchio C, Stotzky G (1998) Binding of DNA on humic acids: effect on transformatiom of bacillus sabtilis and resistance to DNase. Soil Biol Biochem 30:1061-1067

D’Orazio V, Loffredo E, Brunetti G, Senesi N (1999) Triallate adsorption onto humic acids of different origin and nature. Chemosphere 39:183-198

Dai SG, Liu GL, Qian Y, Cheng XK (2001) The sorption behavior of complex pollution system composed of aldicarb and surfactantSDBS. Water Res 35:2286-2290

Deng SB, Bai RB (2004) Adsorption and desorption of humic acid on aminated polyacrylonitrile fibers. J Colloid Interface Sci 280:36-43

Dong XL, Ma LQ, Li YC (2011) Characteristics and mechanisms of hexavalent chromium removal by biochar from sugar beet tailing. J Hazard Mater 190:909-915

Fernández-Ramos C, Ballesteros O, Zafra-Gómez A, Blanc-García R, Navalón A, Crovetto SI, Oliver-Rodríguez B, García-Delgado RA, Vílchez JL (2014) Sorption and desorption of alcohol sulfate surfactants in an agricultural soil. Environ Toxicol Chem 33(3):508-515

Gu ZM, Wang XR, Gu XY, Cao XD, Hu C (2000) Characterization of humic acid extracted from different soils by Fourier transform infrared spectrometry and nuclear magnetic resonance spectroscopy. Chin J Anal Chem 28:314-317 (in Chinese)

Haigh SD (1996) A review of the interaction of surfactants with organic contaminants in soil. Sci Total Environ 185:161-170

Hsieh P-C, Brimblecombe P, Lee C-L, Hsu S-H (2012) The role of the characteristics of humic substances in binding with benzo (h) quinolone. Environ Toxicol Chem 31(2):246-252

Kapoor A, Viraraghavan T (1997) Heavy metal biosorption sites in Aspergillus niger. Bioresour Technol 61(3):221-227

Kasozi GN, Zimmerman AR, Nkedi-Kizza P, Gao B (2010) Catechol and humic acid sorption onto a range of laboratory-produced black carbons (Biochars). Environ Sci Technol 44:6189-6195

Leenheer JA, Ahlrichs JL (1971) A kinetic and equilibrium study of the adsorption of carbaryl and parathion upon soil organic matter surfaces. Soil Sci Soc Am J 35:700-705

Li KB, Lin WP, Xu ZJ, Ma Y (2002) Adsorption and its mechanisms of herbicide bentazone in soil humic acids. Acta Sci Circumst 22:754-758 (in Chinese)

Loffredo E, D'Orazio V, Brunetti G, Senesi N (1999) Adsorption of chlordane onto humic acids from soils and pig slurry. Org Geochem 30:443-451

Lu XQ, Hanna JV, Johnson WD (2000) Source indicators of humic substances: an elemental composition, solid state ${ }^{13} \mathrm{C} \mathrm{CP} / \mathrm{MAS}$ NMR and Py-GC/MS study. Appl Geochem 15:1019-1033

Mao JD, Kong XQ, Schmidt-Rohr K, Pignatello JJ, Perdue EM (2012) Advanced solid-state NMR characterization of marine dissolved organic matter isolated using the coupled reverse osmosis/electrodialysis method. Environ Sci Technol 46:5806-5814

Mattson JS, Mark HB, Malbin MD, Weber WJ, Critten JC (1969) Surface chemistry of active carbon: specific adsorption of phenol. J Colloid Interface Sci 3:116-130

Rodríguez-Cruz MS, Sanchez-Martin MJ, Sanchez-Camazano M (2005) A comparative study of adsorption of an anionic and a non-ionic surfactant by soils based on physicochemical and mineralogical properties of soils. Chemosphere 61:56-64

Rodríguez-Sarmiento DC, Pinzón-Bello JA (2001) Adsorption of sodium dodecylbenzene sulfonate on organophilic bentonites. Appl Clay Sci 18:173-181

Rosell RA, Salfeld JC, Sochtig H (1978) Organic components in argentine soils. 1. nitrogen distribution in soils and their humic acids. Agrochimica 22:98-105

Russell L, Stokes AR, Macdonald H, Muscolo A, Nardi S (2006) Stomatal responses to humic substances and auxin are sensitive to inhibitors of phospholipase $A_{2}$. Plant Soil 283:175-185

Sablayrolles C, Montréjaud-Vignoles M, Silvestre J, Treilhou M (2009) Trace determination of linear alkylbenzene sulfonates: application in artificially polluted soil-carrots System. Int J Anal Chem. doi:10.1155/2009/404836

Senesi N (1992) Binding mechanisms of pesticides to soil humic substances. Sci Total Environ 123(124):63-76

Senesi N, Testini C, Miano TM (1987) Interaction mechanisms between humic acids of different origin and nature and electron donor herbicides: a comparative IR and ESR study. Org Geochem 11:25-30

Senesi N, Brunetti G, Cava PL, Miano TM (1994) Adsorption of alachlor by humic acids from sewage sludge and amended and non-amended soils. Soil Sci 157:176-184

Senesi N, Cava PL, Miano TM (1997) Adsorption of imazethapyr to amended and nonamended soils and humic acids. J Environ Qual 26:1264-1270

Stevenson FJ (1994) Structural basis of humic substances. In: Stevenson FJ (ed) Humus chemistry: genesis, composition, reactions. Wiley, New York

Swift RS (1996) Organic matter characterization. In: Sparks DL (ed) Methods of soil analysis. Soil Sci Soc Am, Madison, WI

US Coast Guard, Department of Transportation (1984) CHRIShazardous chemical data. Volume II. Washington DC: US Government Printing Office

Wang QQ, Yang WC, Liu WP (1999) Adsorption of acetanilide herbicides on soils and its correlation with soil properties. Pestc Sci 55:1103-1108

Xu DP, Xu ZH, Zhu SQ, Cao YZ, Wang Y, Du XM, Gu QB, Li FS (2005) Adsorption behavior of herbicide butachlor on typical soils in China and humic acids from the soil samples. J Colloid Interface Sci 285(1):27-32

Yang M, Wang HB, Dai Y (2002) Research on extractant of humic acid from humic soil and its infrared spectroscopy. J Yunnan Univ Nationalities (Natural Sci Ed) 11:573-574 (in Chinese)

Yao H, Lu J, Wu J, Lu ZY, Wilson PC, Shen Y (2013) Adsorption of fluoroquinolone antibiotics by wastewater sludge biochar: role of the sludge source. Water Air Soil Pollut 224:1370

Yu GF, Qing CL, Mou SS, Wei SQ (2001) Characteristics of mercury adsorption and desorption on humic acids. Acta Sci Circumst 21:601-606 (in Chinese)

Zhao N, Lv YZ, Li GJ (2013) Characterization and three-dimensional structural modeling of humic acid via molecular mechanics and molecular dynamic simulation. Chem Res Chin Univ 29(6):1180-1184 